NEWS RELEASE 24-FEB-2020

\title{
Official EASE journal European Science Editing goes diamond OA with ARPHA
}

\section{PENSOFT PUBLISHERS}

Starting from 2020, European Science Editing (ESE), the official journal of the European Association of Science Editors (EASE), has been relaunched as a fully Open Access journal with all content freely available and published as soon as accepted, on a new journal website hosted on the ARPHA platform.

This move is part of a strategic relaunch of the journal to provide greater focus on research and expert commentary that will inform and support editors working in the scholarly environment. The relaunch comes after several months of planning by a small working group of EASE Council members and ESE editors. Much of the non-research content previously published in the journal will now be published in the newly-created member magazine, the EASE Digest; for example, News notes, The editor's bookshelf, Resources, and interviews.

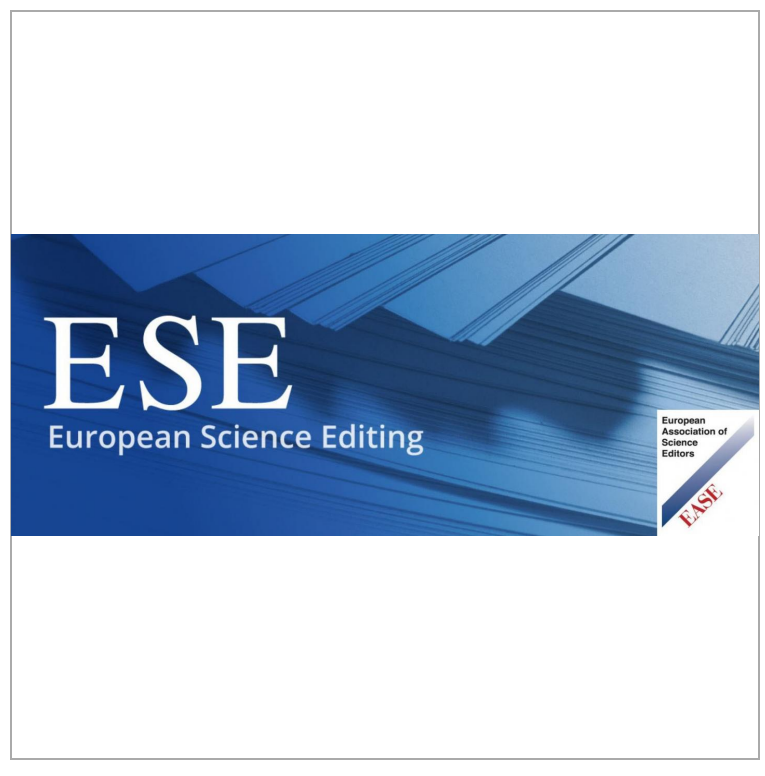

IMAGE: THE EUROPEAN ASSOCIATION OF SCIENCE EDITORS' OFFICIAL JOURNAL EUROPEAN SCIENCE EDITING HAS MOVED TO THE OPEN-ACCESS SCHOLARLY PUBLISHING PLATFORM ARPHA. view more >

CREDIT: EASE AND ARPHA

The journal is being relaunched with a new editorial board, but retaining the same Chief Editor, Ksenija Bazdaric, managing editor Dado Cakalo and associate editors Hrvoje Jakovac, Tom Lang and Joan Marsh. An introductory editorial published in the journal explains the changes.

The new editorial board comprises distinguished members from all over the world: Eva Baranyiova (Czech Republic), Lisa Colledge (UK), Moira Hudson (UK), Olga Kirillova (Russia), Zafer Kocak (Turkey), Rachael Lammey (UK), Vladimir S Lazarev (Belarus), John Loadman (Australia), Herve Maisonneuve (France), Ana Marusic (Croatia), Arjan Polderman (The Netherlands), Maria del Carmen Ruiz Alcocer (Mexico), Karen Shashok (Spain), Cem Uzun (Turkey), and Quan Hoang Vuong (Vietnam).

Ever dedicated to be a source of peer-reviewed information on all aspects of scholarly editing and publishing (i.e. research integrity, peer review, scientometrics, open science, predatory publishing, statistics), writing, translation and ethics, ESE welcomes editorials, original research articles, reviews, viewpoints and correspondence items.

ESE has moved to its new website, provided by the open-access scholarly publishing platform ARPHA (developed by scientific publisher and technology provider Pensoft), for all new articles, although the archive content will remain on the old website. This new website provides better delivery of the journal 
content and will help to make the journal easier to discover.

"I am happy to be working with the ARPHA team and that ESE has moved to a completely new platform which will raise the profile of editorial research and topics." Ksenija Bazdaric, ESE's Chief Editor.

"At EASE we are delighted to be working with ARPHA and Pensoft to publish the journal in its new format. There has been considerable work invested in relaunching the journal with a new focus so that we can raise the profile of research about editing and the value that editors provide in the scholarly environment. An important part of the relaunch was ensuring greater visibility of the journal content and we are confident that ARPHA can help us achieve this." Pippa Smart, President, EASE.

"It could only make us proud at ARPHA that such a pillar in the world of scholarly communication has chosen our publishing platform to make the crucial step towards Open Access," comments ARPHA's and Pensoft's founder and CEO Prof. Lyubomir Penev. "I am certain that by opening up and digitalising its content right away, EASE will greatly facilitate and expedite the improvement of quality and integrity of science on the global scene."

\section{\#\#\#}

Follow European Science Editing on Twitter.

\section{Additional information:}

\section{About EASE}

The European Association of Science Editors (EASE) is an international community of editors from diverse backgrounds, linguistic traditions and professional experience who share an interest in science communication and editing. EASE welcomes members from every corner of the world and has membership in every continent.

The EASE mission is to improve the global standard and quality of science editing by promoting the value of science editors and supporting professional development, research, and collaboration. The three strategic pillars around which EASE focuses its activities are improvement of the global standards; raising the profile of science editors; and supporting professional development.

\section{About ARPHA:}

ARPHA is the first end-to-end, narrative- and data-integrated publishing solution that supports the full life cycle of a manuscript, from authoring to reviewing, publishing and dissemination. ARPHA provides accomplished and streamlined production workflows that can be customized according to the journal's needs. The platform enables a variety of publishing models through a number of options for branding, production and revenue models to choose from.

\section{About Pensoft:}

Pensoft is an independent academic publishing company, well-known worldwide for its innovations in the field of semantic publishing, as well as for its cutting-edge publishing tools and workflows. In 2013, Pensoft launched the first ever end to end XML-based authoring, reviewing and publishing workflow, as demonstrated by the Pensoft Writing Tool (PWT) and the Biodiversity Data Journal (BDJ), now upgraded 
to the ARPHA Publishing Platform. Flagship titles include: Research Ideas and Outcomes (RIO), One Ecosystem, ZooKeys, Biodiversity Data Journal, PhytoKeys, MycoKeys and many more.

\section{Contacts:}

Asst Prof Ksenija Bazdaric, Editor-in-Chief

Email: ese@ease.org.uk

Prof. Lyubomir Penev, ARPHA and Pensoft

Email: penev@pensoft.net

Disclaimer: AAAS and EurekAlert! are not responsible for the accuracy of news releases posted to EurekAlert! by contributing institutions or for the use of any information through the EurekAlert system.

\section{Media Contact}

Lyubomir Penev

penev@pensoft.net

@Pensoft

http://www.pensoft.net $\subsetneq$ 